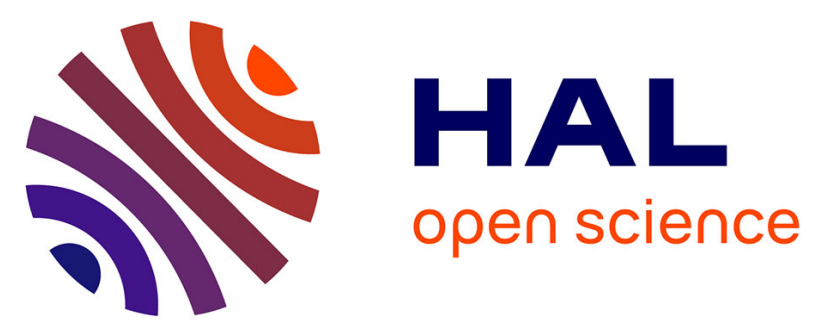

\title{
Regional and temporal heterogeneity of postsystolic wall thickening is associated with left ventricular asynchrony in normal and experimental stunned myocardium.
}

Laurence Lucats, Xavier Monnet, Alain Bizé, Valérie Chetboul, Jean-Louis Pouchelon, Luc Hittinger, Alain Berdeaux, Bijan Ghaleh

\section{To cite this version:}

Laurence Lucats, Xavier Monnet, Alain Bizé, Valérie Chetboul, Jean-Louis Pouchelon, et al.. Regional and temporal heterogeneity of postsystolic wall thickening is associated with left ventricular asynchrony in normal and experimental stunned myocardium.. Basic Research in Cardiology, 2008, 103 (4), pp.385-96. 10.1007/s00395-008-0716-1 . inserm-00315278

HAL Id: inserm-00315278 https://www.hal.inserm.fr/inserm-00315278

Submitted on 7 Apr 2009

HAL is a multi-disciplinary open access archive for the deposit and dissemination of scientific research documents, whether they are published or not. The documents may come from teaching and research institutions in France or abroad, or from public or private research centers.
L'archive ouverte pluridisciplinaire HAL, est destinée au dépôt et à la diffusion de documents scientifiques de niveau recherche, publiés ou non, émanant des établissements d'enseignement et de recherche français ou étrangers, des laboratoires publics ou privés. 
Regional and temporal heterogeneity of postsystolic wall thickening is associated with left ventricular asynchrony in normal and experimental stunned myocardium.

$$
\begin{gathered}
\text { by } \\
\text { Laurence Lucats }^{1,2,3} \text {, Xavier Monnet }{ }^{1,2,3} \text {, Alain Bizé } \\
\text { Valérie Chetboul }^{1,5,3} \text {, Jean-Louis Pouchelon } \\
\end{gathered}
$$$$
\text { Alain Berdeaux }{ }^{1,2,3,4} \text {, Bijan Ghaleh }{ }^{1,2,3,4} \text {. }
$$

1- INSERM, U 841, Equipe 03, Créteil, F-94010, France ;

2- Université Paris 12 Faculté de Médecine, Laboratoire de Pharmacologie, Créteil, F-94000, France ;

3- INSERM U 841, Equipe 03, Ecole Nationale Vétérinaire d’Alfort, Maisons-Alfort, F-94700, France ;

4- AP-HP, Groupe hospitalier Henri Mondor - Albert Chenevier, Fédération de Cardiologie, Créteil, F-94000, France.

5- Unité de Cardiologie d'Alfort, Ecole Nationale Vétérinaire d’Alfort, Maisons-Alfort, F-94700, France.

\author{
Author for correspondance \\ Dr. Bijan GHALEH \\ Laboratoire de Pharmacologie \\ INSERM U 841 Equipe 03 \\ Faculté de Médecine Paris XII \\ 8, rue du Général Sarrail \\ 94010 CRETEIL Cedex \\ France
}

Tel: 33-1-49.81.35.93

Fax: 33-1-49.98.17.77

E-mail: bijan.ghaleh@creteil.inserm.fr 


\begin{abstract}
Aims: Postsystolic wall thickening (PSWT) occurs after aortic valve closure. We investigated the influence of ischemia location and wall interactions on PSWT in normal and stunned myocardium.
\end{abstract}

Methods and Results: 22 dogs were studied. Seven chronically instrumented dogs (sonomicrometry) underwent 10-min coronary artery occlusion (CAO) of left circumflex artery (“LCX stunning”) and 7 other dogs underwent 10-min CAO of the anterior descending artery ("LAD stunning”) followed by reperfusion. At baseline, there was no PSWT in the anterior wall whereas posterior wall started and finished to thicken after the anterior wall, demonstrating PSWT. With LCX stunning, PSWT was observed in the posterior wall without affecting the remote anterior wall. With LAD stunning, PSWT in the anterior wall was transient and of lower magnitude vs posterior wall; in the remote posterior wall, PSWT previously observed at baseline, almost vanished. Postsystolic to systolic wall thickening ratio identified (ROC analysis) normal, ischemic and stunned myocardium with different amplitudes between walls. Tissue Doppler Imaging demonstrated similar pattern in basal, mid and apical segments (additional $\mathrm{n}=4$ for both LCX and LAD stunning).

Conclusion: The present study demonstrates that location of ischemia and wall interactions produce discrepancies in PSWT between anterior and posterior walls in stunned myocardium. 


\section{KEYWORDS}

Myocardial stunning

Regional function

Systole

Postsystolic wall thickening 


\section{INTRODUCTION}

Postsystolic wall thickening (PSWT) is a part of the left ventricular thickening that occurs after aortic valve closure $[1-3,6,8,14-16,18,19,22,30,32,34,35]$ and is a marker of left ventricular asynchrony [5] which has been extensively described during experimental [1, 2, 10, 13, 15, 16, 20, 29, 35, 36] and clinical [12, 14, 39] myocardial ischemia. The mechanisms involved in this phenomenon remain however still unclear and depend on the level of wall thickening and/or ischemic substrate [28]. Whether it is a passive recoil of the elastic myocardium and/or an active delayed contraction is still under debate [30].

Measurement of postsystolic wall motion has been proposed as a tool to assess the viability, to predict the recovery of left ventricular function during ischemic episodes and to evaluate the improvement of systolic performance during cardiac resynchronization therapy [2, 12, 29, 31, 35]. This issue is still debated and the presence of PSWT might not be an invariable marker of segment viability during ischemia and may not be always considered as pathognomonic of myocardial disease [34]. Part of this debate might result from regional heterogeneity as postsystolic wall motion is observed in approximately one-third of myocardial segments in healthy subjects $[1,39]$. Posterior and anterior walls are indeed submitted to different stretching stresses and their extent and timing of thickening are therefore different [24, 41, 42]. To date, most of the studies investigated postsystolic wall motion while ischemia was produced either at the level of the anterior $[4,27-30,35,36]$ or the posterior [15, 16, 33] walls but to our knowledge, they had not been compared in the same experimental setting. Our hypothesis was

that part of the confusion surrounding PSWT is the consequence of different experimental settings among the studies. Indeed, the locations of the ischemia are and of the investigated stunned segment within the left ventricle are of major importance. 
The goal of this study was thus to investigate the influence of ischemia location and wall interactions on the significance of PSWT in the normal and stunned myocardium. The evolution of PSWT was measured at baseline, during brief ischemia and subsequent stunning of either left ventricular anterior or posterior walls measured in the ischemic and the remote non ischemic zones. For this purpose, we performed occlusions of either the left anterior descending (LAD) or the left circumflex (LCX) coronary arteries in conscious dogs chronically instrumented with sonomicrometry. This model allows reproducible and repeatable measurements of regional myocardial thickening without interference with anesthetic agents [37]. Moreover, as instrumentation with multiple ultrasonic crystals is rather difficult (e.g., apical, mid or basal within anterior and posterior walls), additional experiments in conscious state were performed using Tissue Doppler Imaging [40]. 


\section{METHODS}

The animal instrumentation and the experiments were performed in accordance with the official regulations of the French Ministry of Agriculture.

\section{Instrumentation}

As previously described [25], a left thoracotomy was performed in dogs (18 - $25 \mathrm{~kg})$ and fluid-filled Tygon catheters were placed in the descending thoracic aorta as well as the left atrium for measurement of blood pressure. A solid-state pressure transducer (P7A, Konigsberg Instruments; Pasadena, CA, USA) was introduced into the apex of the left ventricle (LV). Pneumatic occluders were placed around the left circumflex coronary artery (LCX) and the left anterior descending coronary artery (LAD) at 2-3 cm from its origin. Two pairs of ultrasonic crystals were used for measurement of LV wall thickening in the distribution of LCX (posterior wall, so-called inferior wall in humans) and LAD (anterior wall) vascular beds. One crystal was implanted within the endocardium and the other was sutured to the epicardium in the mid region of the left ventricle. Proper alignment of the crystals was ensured by visualizing the signal on an oscilloscope. The pericardium was sutured after implanting the crystals. All catheters and wires were exteriorized between the scapulae and the pneumothorax was evacuated. Cefazolin ( $1 \mathrm{~g}$ iv) and gentamicin (40 mg iv) were administered before and during the first week after surgery. Postoperative analgesia was provided with morphine. The correct position of the crystals was verified at autopsy. 


\section{Hemodynamic measurements}

All hemodynamic data were recorded and analyzed using the data acquisition software HEM v3.5 (Notocord Systems, Croissy sur Seine, France). Aortic and left atrial pressures were measured with a Statham P23 ID strain-gauge transducer (Gould-Nicolet, Courtaboeuf, France). $\mathrm{LV}$ pressure was measured using the Konigsberg gauge and the change in LV pressure over time (LV dP/dt) was computed from the LV pressure signal. LV pressure was calibrated in vitro with a mercury manometer and in vivo with the left atrial and aortic pressures. External electrocardiogram was also recorded.

\section{Measurements of regional contraction}

Wall thicknesses were obtained by using an ultrasonic transit-time dimension gauge (Module 201, System 6, Triton Technology Inc., San Diego, CA, USA). To determine wall thickening, end-diastolic wall thickness was measured at the initiation of the upstroke of LV pressure tracing and the end-systolic wall thickness was measured 20 ms before peak negative LV dP/dt [35].

As illustrated in Figure 1, systolic wall thickening was defined as the difference between enddiastolic and end-systolic wall thicknesses, i.e., the wall thickening (expressed in \% vs enddiastolic wall thickness) that occurs during the ejection period [9].

Maximal wall thickness was defined as the maximal distance between crystals, measured after aortic valve closure. Postsystolic wall thickening was defined as the maximal minus end-systolic wall thicknesses, i.e., the wall thickening that occurs after the ejection period. 
Minimal early systolic wall thickness was defined as the minimal distance between crystals measured after end diastole during the ejection period. Early systolic thinning was defined as the end-diastolic minus minimal early systolic wall thicknesses.

The time to onset of wall thickening ( $\left.\mathrm{T}_{\text {onset }}\right)$ was calculated as the time elapsed between enddiastole and the minimal early systolic wall thickness. Asynchrony of thickening between the posterior and the anterior walls was evaluated by $\Delta_{\text {onset }}=\mathrm{T}_{\text {onset }}$ [posterior wall] $-\mathrm{T}_{\text {onset }}$ [anterior wall].

\section{Measurement of regional myocardial blood flows}

Regional myocardial blood flows were measured by the fluorescent microspheres techniques, as previously reported [26]. Microspheres labeled with fluorescent dyes (FluoSpheres, Triton System, San Diego, CA) were injected via the left atrial catheter. Arterial blood reference samples were withdrawn $(7.5 \mathrm{ml} / \mathrm{min}$ during $2 \mathrm{~min})$.

At termination of the study, the hearts were excised. The anatomical boundaries of the previously ischemic and nonischemic vascular beds were defined by dual perfusion of dyes in the left main coronary artery which was perfused with a solution of 3\% Evans blue. The previously occluded circumflex or left anterior descending arteries were simultaneously perfused with saline. The heart was then cut into slices. Pictures were taken and the area at risk, i.e., the non blue zone, was quantified by image analysis.

The slices were further divided into subendocardium, midmyocardium and subepicardium layers. Samples were processed to extract the fluorescence, and blood flows (expressed as 
$\mathrm{ml} / \mathrm{min} / \mathrm{g}$ of myocardium) were calculated. Mean transmural flow was calculated as the combined flow of all three layers.

Tissue Doppler Imaging

An ultrasound system (Vivid 7, General Electric Medical System, Waukesha, WI, USA) and a 5-MHz phased-array transducer were used to analyse regional velocity of basal, mid and apical segments of the anterior and the posterior wall. Three beats of cardiac cycles in sinus rhythm were acquired to assess radial function. End-diastole and end-systole were first detected using aortic Doppler signal which was used to trigger the electrocardiogram. Timing of end-systole and end-diastole were then set according to the electrocardiogram.

\section{Experimental protocol}

Three weeks after instrumentation, when the dogs had fully recovered from their initial instrumentation, they were installed to lie quietly on a table in the conscious state. All animals received an injection of morphine sulfate $(0.2 \mathrm{mg} / \mathrm{kg} \mathrm{SC})$ before coronary artery occlusion (CAO). After baseline measurements, a group of 7 dogs underwent a 10-min CAO of the LCX (so-called “LCX stunning” group) and a second group of 7 other dogs underwent a 10-min CAO of the LAD (so-called “LAD stunning” group). All hemodynamic and wall thickness parameters were continuously recorded and calculated at baseline, during CAO $\left(9^{\text {th }} \mathrm{min}\right)$ and during the 6 hours of the subsequent reperfusion. Regional myocardial blood flows with the use of microspheres were measured during CAO $\left(6^{\text {th }} \mathrm{min}\right)$. For Tissue Doppler Imaging purposes, two additional groups of animals (both $n=4$ ) underwent the same ischemia-reperfusion sequence. Echocardiographic measurements were performed at baseline and at 30 min of reperfusion. 
Statistical Analysis

Data are reported as mean \pm S.E.M. Comparisons were performed using two-way ANOVA for repeated measures. If needed, only single individual comparisons between LAD stunning vs LCX stunning were conducted using Student $t$-test. Regression lines were calculated with the leastsquares method. Receiver operating characteristics (ROCs) analysis were used to interpret values of postsystolic to systolic wall thickening ratio as well as postsystolic wall thickening in LCX stunning and LAD stunning. Sensitivity, specificity and area under curve (AUC) were calculated. A value of $p<0.05$ was considered significant. 


\section{RESULTS}

\section{Hemodynamics}

Representative recordings of hemodynamics, regional function by sonomicrometry and electrocardiogram are displayed in Figure 2. As shown in Table 1, heart rate, mean aortic

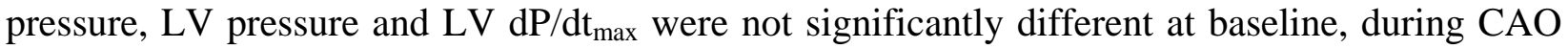
and reperfusion between the two groups of dogs. Regional myocardial blood flows measured were similar during CAO between the LAD and LCX groups $(0.08 \pm 0.05 \mathrm{ml} / \mathrm{min} / \mathrm{g}, \mathrm{n}=4$, and $0.10 \pm 0.06 \mathrm{ml} / \mathrm{min} / \mathrm{g}, \mathrm{n}=5$, respectively). Areas at risk were similar in both groups $(29 \pm 6 \%$ and $31 \pm 4 \%$, both $n=7$, respectively). As illustrated in Figure 2, there was no QRS prolongation during reperfusion.

Systolic wall thickening

Values of systolic wall thickening were not significantly different at baseline between the two groups (e.g., $27 \pm 2$ and $26 \pm 3 \%$ in the posterior wall for the LCX stunning group and in the anterior wall for the LAD stunning group, respectively). As illustrated in Figure 3, systolic wall thickening measured in the ischemic zone was severely depressed during CAO. During reperfusion, systolic wall thickening remained similarly depressed in the ischemic zones with both LCX and LAD stunning. In the remote non ischemic zone, systolic wall thickening remained unchanged with LCX or LAD stunning (Figure 3). 


\section{Postsystolic wall thickening}

As illustrated in Figure 4, PSWT was observed at baseline in the posterior but not in the anterior wall. During CAO, PSWT in the ischemic zone was significantly greater after LCX vs LAD occlusions (13 \pm 1 and $8 \pm 2 \%$, respectively). As illustrated in Figure 4A, this difference was observed throughout the first hour of reperfusion.

In the remote non ischemic zone (Figure 4B), posterior PSWT decreased during LAD occlusion and early reperfusion (30 min) with LAD stunning. After that time-point, PSWT was again observed and tended to reach greater values as compared to baseline. In contrast, PSWT was not observed in the anterior wall at baseline and it remained not affected by LCX occlusion and subsequent stunning.

Asynchrony between the ischemic and the remote non ischemic zones: delayed wall thickening, early systolic wall thinning and postsystolic wall thickening

At baseline, there was a "physiological asynchrony" within the left ventricle: the posterior wall started to thicken after the anterior wall $\left(\Delta_{\text {onset }}=20 \pm 5 \mathrm{~ms}\right)$ and during this delay, wall thickening was replaced by a paradoxical early systolic wall thinning $(0.10 \pm 0.02 \mathrm{~mm}$ in the 14 dogs) (Figures 1 and 5). Posterior wall also finished to thicken after the anterior wall, i.e., demonstrating PSWT (0.54 $\pm 0.15 \mathrm{~mm}$ in the 14 dogs). During myocardial stunning induced by LCX occlusion and reperfusion, the delay was increased as indicated by the arrow in Figure 5 (higher values of $\Delta_{\text {onset}}$ ) and completion of PSWT was also delayed, i.e., PSWT was increased. The overall timing in thickening of the non ischemic anterior wall was not affected by posterior wall stunning. 
In the anterior wall, there was no delay in wall thickening at baseline and therefore no paradoxical early systolic wall thinning. During myocardial stunning induced by LAD occlusion and reperfusion, a delay in wall thickening was observed in the anterior wall during LAD stunning as indicated by the arrow in Figure 5 (negative values of $\Delta_{\text {onset). This delay was then }}$ accompanied by a paradoxical early systolic wall thinning and completion of anterior wall thickening was delayed, i.e., PSWT was observed with LAD stunning. During LAD stunning, the "physiological asynchrony" of left ventricular walls was reversed: the posterior wall started to thicken without any delay before the anterior wall but it also finished to thicken before the anterior wall, i.e., PSWT was not observed in the remote non ischemic posterior wall.

Importantly, the presence of a delay in wall thickening was always associated with an early systolic wall thinning and at that time, completion of wall thickening was also delayed, i.e., there was PSWT. As illustrated in Figure 6, the evolution of PSWT in both zones was related to that of early systolic wall thinning with significant correlations between postsystolic wall thickening and early systolic wall thinning as well as between the duration of postsystolic wall thickening and the delay in wall thickening. Conversely, as illustrated in the anterior wall during LCX stunning, PSWT was not observed in the absence of a delay in wall thickening, i.e., in the absence of systolic wall thinning.

\section{Interpretation of postsystolic wall thickening}

By ROC analysis, postsystolic to systolic wall thickening ratio was the best parameter to identify myocardial ischemia (cutoff: 1.7 ; sensitivity: $100 \%$, specificity: $97 \%$, AUC $=0.997$, $\mathrm{p}<0.05$ in the anterior wall and cutoff: 1.1 ; sensitivity: $100 \%$, specificity: $95 \%$, AUC $=0.993$, $\mathrm{p}<0.05$ in the posterior wall) as illustrated in Figure 6. Postsystolic to systolic wall thickening 
ratio further allowed to distinguish between normal and stunned myocardium in the anterior wall (cutoff: 0.09; sensitivity: 53\%; specificity: 100\%; AUC $=0.802 ; \mathrm{p}<0.05$ ) and in the posterior wall (cutoff: 0.3; sensitivity: 53\%; specificity: 95\%; AUC $=0.696 ; \mathrm{p}<0.05$ ). ROCs analysis of the ratios showed that the cutoff values were lower for the anterior wall as compared to the posterior wall reflecting that the absolute value of PSWT was of higher amplitude.

\section{Tissue Doppler Imaging}

As illustrated in Figure 8, echocardiographic measurements demonstrated that at baseline, PSWT was a) absent in the anterior wall in basal, mid and apical segments and b) present in the posterior wall in basal, mid and apical segments. During stunning of the anterior wall (LAD stunning), postsystolic wall motion was observed in the mid and apical segments. Its absence in the basal segment was explained by the location of the occluder. At that time, postystolic wall motion was no longer present in the remote posterior wall. During stunning of the posterior wall (LCX stunning), postsystolic wall motion was exacerbated in all segments as compared to baseline measurements; no postystolic wall motion was observed in the remote anterior wall. 


\section{DISCUSSION}

The present study investigated for the first time the consequences of anterior and posterior ischemia and subsequent stunning on postsystolic wall thickening measured simultaneously in the anterior and posterior ventricular walls. Postsystolic wall thickening was strikingly different between the anterior and the posterior walls. Despite the same pathophysiological context, postsystolic wall thickening was greater in the posterior than in the anterior wall as a result of the physiological (at baseline) or the pathological (at least with stunning) asynchrony and wall interactions within the left ventricle. Therefore, interpretation of postsystolic wall thickening should not only be analyzed along with systolic performance but it needs also to take into account the locations of regional ischemia and the considered segment (anterior vs posterior wall) as demonstrated by ROCs analyses.

Aynchrony and postsystolic wall thickening

We observed that in the normal heart, thickening of the posterior wall started later than in the anterior wall. This delay occurred during isovolumic contraction when LV pressure is rapidly increasing. During this time-period, one can speculate that the non-thickening posterior myocardium was stretched under pressure and normal thickening was replaced by a paradoxical early systolic wall thinning. During stunning of the posterior wall, both the delay in posterior wall thickening and early systolic wall thinning were increased. As shown by the increase in $\Delta_{\text {onset}}$, myocardial stunning of the posterior wall exacerbated left ventricular asynchrony. This delay in the onset of thickening was accompanied by a prolongation of thickening after aortic valve closure, demonstrating PSWT. This relationship between the presence of PSWT and the delay of thickening at early systole, i.e., the result of asynchrony, was further supported by the 
correlation between PSWT and early systolic wall thinning. Interestingly, when posterior myocardial stunning declined, the asynchrony between anterior and posterior walls tended to return to baseline. In these conditions, $\Delta_{\text {onset, }}$ early systolic wall thinning and PSWT were simultaneously reduced. This delay in contraction observed in the posterior wall was not observed in a previous study investigating the consequences of LAD and LCX stunning. However, it should be stressed that these authors used an anesthetized open-chest model and a pericardial cradle which might have altered myocardial contraction [7].

If this relationship between ventricular asynchrony and PSWT described above is real, one can speculate that when there is no delay in wall thickening and when early systolic wall thinning tends to zero, PSWT should not be detected anymore. This is the case in our study as there was no delay for the anterior wall to thicken (early systolic wall thinning $=0 \mathrm{~mm}$ at baseline) and PSWT was not observed in this zone. This mechanism can also explain the behavior of PSWT during LAD stunning. Indeed, due to stunning, thickening of the anterior wall was delayed and $\Delta_{\text {onset }}$ became negative, i.e., the posterior wall started to thicken before the anterior wall. In this situation, posterior thickening was not delayed anymore ( $\mathrm{T}_{\text {onset }}$ and early systolic wall thinning close to 0) and posterior PSWT almost vanished during the first hour of anterior wall stunning. Conversely, thickening of the anterior wall was delayed and PSWT in the anterior zone was observed in these conditions. Such relationship between ischemia location within the left ventricle and the mechanical consequences have been previously reported during acute myocardial ischemia [11].

As discussed above, the presence of PSWT appears to result from a ventricular asynchrony. We did not attempt to distinguish between a passive recoil or an active contraction. On the one 
hand, as myocardium is an elastic structure, PSWT might be the result of a restitution of early systolic thinning. On the other hand, it could also correspond to a delayed active contraction.

As one hallmark of myocardial ischemia was a depressed wall thickening during ejection, we further analyzed the significance of PSWT by also taking into account systolic wall thickening. Previous reports $[19,38]$ have performed similar analysis but they only proposed a single cut-off value for the entire ventricle without distinguishing anterior and posterior walls or taking into account the location of the ischemia. As illustrated in Figure 7, the present study demonstrated that cut-off values used to distinguish between the normal, ischemic and stunned myocardium are strikingly different between the anterior and the posterior wall. These values are much lower in the anterior wall as compared to the posterior wall. This demonstrates that PSWT might not be always considered as pathognomonic of myocardial dysfunction. Its clinical application would be improved by taking into account such heterogeneity. In addition, its measurement can provide interesting informations on the drugs effect on left ventricular function and wall interactions. For example, in a previous study, using this index, we have demonstrated that ivabradine, a pure heart rate reducing agent, converts the wasted postsystolic wall thickening into efficient ejectional wall thickening [23].

Our experimental model is well appropriate for studying regional wall thickening as all recordings were made in conscious animals, avoiding changes in loading conditions and the use of anesthetic agents [17] which are well known to interfere with myocardial performance [37]. Two segments were measured and analyzed in our study as compared to MRI [21, 42] but assessment of myocardial thickening during hours in stable conditions is not possible in anesthetized or open-chest models. Sonomicrometry crystals are long term implanted and the measure that they provide is highly reproducible whereas echocardiography can hardly provide 
similar repetitive and reproducible measurements during hours. Nevertheless using Tissue Doppler Imaging, we demonstrated that the results obtained with sonomicrometry on mid segments were also observed in basal, mid and apical segments. Unfortunately due to an insufficient optimal positioning of the echocardiographic probe and a time consuming process, it was not possible to perform quantitative and repetitive Tissue Doppler Imaging measurements in the conscious dogs. The development of other echocardiographic approaches such as speckle tracking will probably solve in the future the limitations encountered in the present study.

In conclusion, the present study demonstrates that location of regional ischemia and wall interactions are responsible for great discrepancies in postsystolic wall motion between the anterior and posterior walls of the stunned myocardium. 


\section{ACKNOWLEDGMENTS}

Laurence Lucats was supported by a fellowship from INSERM (“poste d'accueil”) and a grant

from the Académie Nationale de Médecine. The authors are greatly indebted to Dr Guy Heyndrickx for fruitful discussion during the elaboration of this manuscript. 


\section{REFERENCES}

1. Birkeland S, Hexeberg E (1994) Is postsystolic shortening area always a marker of myocardial ischaemia? Acta Physiol Scand 151:269-277

2. Brown MA, Norris RM, Takayama M, White HD (1987) Post-systolic shortening: a marker of potential for early recovery of acutely ischaemic myocardium in the dog. Cardiovasc Res 21:703-716

3. Citro R, Galderisi M (2005) Myocardial postsystolic motion in ischemic and not ischemic myocardium: the clinical value of tissue Doppler. Echocardiography 22:525-532

4. Derumeaux G, Ovize M, Loufoua J, Pontier G, Andre-Fouet X, Cribier A (2000) Assessment of nonuniformity of transmural myocardial velocities by color-coded tissue Doppler imaging: characterization of normal, ischemic, and stunned myocardium. Circulation 101:13901395

5. Ehring T, Heusch G (1990) Left ventricular asynchrony: an indicator of regional myocardial dysfunction. Am Heart J 120:1047-1057

6. Ehring T, Heusch G (1991) Postextrasystolic potentiation does not distinguish ischaemic from stunned myocardium. Pflugers Arch 418:453-461

7. Fan D, Soei LK, Stubenitsky R, Boersma E, Duncker DJ, Verdouw PD, Krams R (1997) Contribution of asynchrony and nonuniformity to mechanical interaction in normal and stunned myocardium. Am J Physiol 273:H2146-2154 
8. Gaasch WH, Blaustein AS, Bing OH (1985) Asynchronous (segmental early) relaxation of the left ventricle. J Am Coll Cardiol 5:891-897

9. Guth BD, Schulz R, Heusch G (1990) Evaluation of parameters for the assessment of regional myocardial contractile function during asynchronous left ventricular contraction. Basic Res Cardiol 85:550-562

10. Heusch G, Guth BD, Widmann T, Peterson KL, Ross J, Jr. (1987) Ischemic myocardial dysfunction assessed by temporal Fourier transform of regional myocardial wall thickening. Am Heart J 113:116-124

11. Hoit BD, Lew WY (1988) Functional consequences of acute anterior vs. posterior wall ischemia in canine left ventricles. Am J Physiol 254:H1065-1073

12. Hosokawa H, Sheehan FH, Suzuki T (2000) Measurement of postsystolic shortening to assess viability and predict recovery of left ventricular function after acute myocardial infarction. J Am Coll Cardiol 35:1842-1849

13. Ihara T, Komamura K, Shen YT, Patrick TA, Mirsky I, Shannon RP, Vatner SF (1994) Left ventricular systolic dysfunction precedes diastolic dysfunction during myocardial ischemia in conscious dogs. Am J Physiol 267:H333-343

14. Jamal F, Kukulski T, D'Hooge J, De Scheerder I, Sutherland G (1999) Abnormal postsystolic thickening in acutely ischemic myocardium during coronary angioplasty: a velocity, strain, and strain rate doppler myocardial imaging study. J Am Soc Echocardiogr 12:994-996

15. Jamal F, Kukulski T, Strotmann J, Szilard M, D'Hooge J, Bijnens B, Rademakers F, Hatle L, De Scheerder I, Sutherland GR (2001) Quantification of the spectrum of changes in regional 
myocardial function during acute ischemia in closed chest pigs: an ultrasonic strain rate and strain study. J Am Soc Echocardiogr 14:874-884

16. Jamal F, Szilard M, Kukulski T, Liu XS, D'Hooge J, Bijnens B, Rademakers F, Hatle L, Descheerder I, Sutherland GR (2001) Changes in systolic and postsystolic wall thickening during acute coronary occlusion and reperfusion in closed-chest pigs: Implications for the assessment of regional myocardial function. J Am Soc Echocardiogr 14:691-697

17. Kanaya N, Fujita S (1994) The effects of isoflurane on regional myocardial contractility and metabolism in "stunned" myocardium in acutely instrumented dogs. Anesth Analg 79:447454

18. Knight DR, Shen YT, Thomas JX, Jr., Randall WC, Vatner SF (1988) Sympathetic activation induces asynchronous contraction in awake dogs with regional denervation. Am J Physiol 255:H358-365

19. Kukulski T, Jamal F, Herbots L, D'Hooge J, Bijnens B, Hatle L, De Scheerder I, Sutherland GR (2003) Identification of acutely ischemic myocardium using ultrasonic strain measurements. A clinical study in patients undergoing coronary angioplasty. J Am Coll Cardiol 41:810-819

20. Kumada T, Gallagher KP, Shirato K, McKown D, Miller M, Kemper WS, White F, Ross J, Jr. (1980) Reduction of exercise-induced regional myocardial dysfunction by propranolol. Studies in a canine model of chronic coronary artery stenosis. Circ Res 46:190-200

21. Leclercq C, Faris O, Tunin R, Johnson J, Kato R, Evans F, Spinelli J, Halperin H, McVeigh E, Kass DA (2002) Systolic improvement and mechanical resynchronization does not 
require electrical synchrony in the dilated failing heart with left bundle-branch block. Circulation 106:1760-1763

22. Lew WY, Rasmussen CM (1989) Influence of nonuniformity on rate of left ventricular pressure fall in the dog. Am J Physiol 256:H222-232

23. Lucats L, Ghaleh B, Monnet X, Colin P, Bize A, Berdeaux A (2007) Conversion of postsystolic wall thickening into ejectional thickening by selective heart rate reduction during myocardial stunning. Eur Heart J 28:872-879

24. McVeigh ER, Prinzen FW, Wyman BT, Tsitlik JE, Halperin HR, Hunter WC (1998) Imaging asynchronous mechanical activation of the paced heart with tagged MRI. Magn Reson Med 39:507-513

25. Monnet X, Colin P, Ghaleh B, Hittinger L, Giudicelli JF, Berdeaux A (2004) Heart rate reduction during exercise-induced myocardial ischaemia and stunning. Eur Heart J 25:579-586

26. Monnet X, Ghaleh B, Colin P, de Curzon OP, Giudicelli JF, Berdeaux A (2001) Effects of heart rate reduction with ivabradine on exercise-induced myocardial ischemia and stunning. J Pharmacol Exp Ther 299:1133-1139

27. Pislaru C, Bruce CJ, Anagnostopoulos PC, Allen JL, Seward JB, Pellikka PA, Ritman EL, Greenleaf JF (2004) Ultrasound strain imaging of altered myocardial stiffness: stunned versus infarcted reperfused myocardium. Circulation 109:2905-2910

28. Pislaru C, Bruce CJ, Seward JB, Greenleaf JF (2004) Distinctive changes in end-diastolic wall thickness and postsystolic thickening in viable and infarcted myocardium. J Am Soc Echocardiogr 17:855-862 
29. Rose J, Schulz R, Martin C, Heusch G (1993) Post-ejection wall thickening as a marker of successful short term hibernation. Cardiovasc Res 27:1306-1311

30. Skulstad H, Edvardsen T, Urheim S, Rabben SI, Stugaard M, Lyseggen E, Ihlen H, Smiseth OA (2002) Postsystolic shortening in ischemic myocardium: active contraction or passive recoil? Circulation 106:718-724

31. Sogaard P, Egeblad H, Kim WY, Jensen HK, Pedersen AK, Kristensen BO, Mortensen PT (2002) Tissue Doppler imaging predicts improved systolic performance and reversed left ventricular remodeling during long-term cardiac resynchronization therapy. J Am Coll Cardiol 40:723-730

32. Song JK, Song JM, Kang DH, Haluska B, Marwick TH (2004) Postsystolic thickening detected by Doppler myocardial imaging: a marker of viability or ischemia in patients with myocardial infarction. Clin Cardiol 27:29-32

33. Song JM, Kim JH, Kim YH, Lee SW, Yoon YJ, Kim J, Kang DH, Song JK (2003) Temporal changes and histologic relation of postsystolic thickening in an animal model of acute ischemia and reperfusion. J Am Soc Echocardiogr 16:409-414

34. Sutherland GR (2004) Do regional deformation indexes reflect regional perfusion in all ischemic substrates? J Am Coll Cardiol 44:1672-1674

35. Takayama M, Norris RM, Brown MA, Armiger LC, Rivers JT, White HD (1988) Postsystolic shortening of acutely ischemic canine myocardium predicts early and late recovery of function after coronary artery reperfusion. Circulation 78:994-1007 
36. Urheim S, Edvardsen T, Steine K, Skulstad H, Lyseggen E, Rodevand O, Smiseth OA (2003) Postsystolic shortening of ischemic myocardium: a mechanism of abnormal intraventricular filling. Am J Physiol Heart Circ Physiol 284:H2343-2350

37. Vatner SF, Braunwald E (1975) Cardiovascular control mechanisms in the conscious state. N Engl J Med 293:970-976

38. Voigt JU, Exner B, Schmiedehausen K, Huchzermeyer C, Reulbach U, Nixdorff U, Platsch G, Kuwert T, Daniel WG, Flachskampf FA (2003) Strain-rate imaging during dobutamine stress echocardiography provides objective evidence of inducible ischemia. Circulation 107:2120-2126

39. Voigt JU, Lindenmeier G, Exner B, Regenfus M, Werner D, Reulbach U, Nixdorff U, Flachskampf FA, Daniel WG (2003) Incidence and characteristics of segmental postsystolic longitudinal shortening in normal, acutely ischemic, and scarred myocardium. J Am Soc Echocardiogr 16:415-423

40. Weidemann F, Kowalski M, D'Hooge J, Bijnens B, Sutherland GR (2001) Doppler myocardial imaging. A new tool to assess regional inhomogeneity in cardiac function. Basic Res Cardiol 96:595-605

41. Wyman BT, Hunter WC, Prinzen FW, McVeigh ER (1999) Mapping propagation of mechanical activation in the paced heart with MRI tagging. Am J Physiol 276:H881-891

42. Zwanenburg JJ, Gotte MJ, Kuijer JP, Heethaar RM, van Rossum AC, Marcus JT (2004) Timing of cardiac contraction in humans mapped by high-temporal-resolution MRI tagging: early 
onset and late peak of shortening in lateral wall. Am J Physiol Heart Circ Physiol 286:H18721880 


\section{FIGURE LEGENDS}

\section{Figure 1}

Typical waveform representing the evolution of myocardial wall thickness during a single beat recorded from a stunned posterior wall: (a) systolic wall thickening was defined as the difference between end-diastolic and end-systolic wall thicknesses; (b) maximal wall thickness was defined as the maximal distance between crystals measured after end-systole; postsystolic wall thickening was defined as the maximal minus end-systolic wall thicknesses; (c) minimal early systolic wall thickness was defined as the minimal distance between crystals measured after end-diastole. Early systolic wall thinning was defined as the end-diastolic minus minimal wall thicknesses; (d) the time to onset of wall thickening $\left(\mathrm{T}_{\text {onset }}\right)$ was calculated as the time elapsed between enddiastole and the early systolic minimal wall thickness. These measurements were performed using both sonomicrometry (left panel) and Tissue Doppler Imaging techniques (right panel; AVO : aortic valve opening; AVC : aortic valve closure).

\section{Figure 2}

Representative recordings of aortic blood and left ventricular pressures, left ventricular pressure first derivative ( $\mathrm{LV} \mathrm{dP} / \mathrm{dt}$ ), anterior wall thickness, posterior wall thickness and electrocardiogram measured at (a) baseline, (b) during a 10 min of left circumflex coronary artery occlusion (LCX CAO), (c) during myocardial stunning of the posterior wall after a 10-min coronary artery occlusion of the left circumflex coronary artery (LCX stunning), (d) during a 10 min of left anterior descending coronary artery occlusion (LAD CAO) and (e) during myocardial stunning of the anterior wall after a 10-min coronary artery occlusion of the left anterior descending coronary artery (LAD stunning). 
Figure 3

Evolution of systolic wall thickening (\% change from baseline) in the ischemic zone and remote non ischemic zone measured at baseline, during a 10-min coronary artery occlusion (CAO, $9^{\text {th }}$ min recording) and reperfusion of the left anterior descending coronary artery (LAD stunning, $n=7$ ) and the left circumflex coronary artery (LCX stunning, $n=7$ ). The severities of myocardial stunning in the two zones were similar.

\section{Figure 4}

(A). Evolution of postsystolic wall thickening in the ischemic zone measured during a 10 minperiod of coronary artery occlusion (CAO) and reperfusion of either the left anterior descending coronary artery (LAD stunning, $n=7$ ) or the left circumflex coronary artery (LCX stunning, $n=7$ ).

(B). Evolution of postsystolic wall thickening in the non ischemic zone measured during the 10-min CAO and reperfusion of either the left anterior descending coronary artery (LAD stunning, $n=7$ ) or the left circumflex coronary artery (LCX stunning, $n=7$ ). ${ }^{\star}, p<0.05$ vs. LAD stunning.

Figure 5

Illustration of the asynchrony between the anterior and posterior walls at baseline and during myocardial stunning. At baseline, there was no delay in wall thickening in the anterior wall but posterior wall exhibited a delayed wall thickening as compared to anterior wall (as evaluated by $\left.\Delta_{\text {onset }}\right)$, i.e., posterior wall started to thicken after the anterior wall. This delay was characterized by two aspects: firstly, during this early systolic time-delay, the posterior wall paradoxically 
thinned and secondly, wall thickening continued beyond end-systole, i.e. postsystolic wall thickening was observed.

During myocardial stunning induced by LCX occlusion and reperfusion (LCX stunning), the delay to thickening was increased as indicated by the arrow (increased positive $\Delta_{\text {onset }}$ ) and both early systolic wall thinning and postystolic wall thickening were exaggerated with LCX stunning (tracing recorded at $1 \mathrm{~h}$ of reperfusion).

During myocardial stunning induced by LAD occlusion and reperfusion, as indicated by the arrow, a delay in wall thickening was observed in the anterior wall and was accompanied by a paradoxical early systolic wall thinning. Concomitantly, completion of anterior wall thickening was also delayed, i.e., postystolic wall thickening was observed. In this situation, $\Delta_{\text {onset }}$ was negative, i.e., the posterior wall started to thicken without any delay before the anterior wall. Posterior wall also finished to thicken before the anterior wall, i.e., postsystolic wall thickening was not observed anymore in the remote non ischemic posterior wall (tracing recorded at $1 \mathrm{~h}$ of reperfusion).

Figure 6

A. Correlation between postsystolic wall thickening and early systolic wall thinning in the ischemic zones measured either in the left anterior descending coronary artery (LAD stunning, $n=7$, Postsystolic wall thickening $=1.35^{*}$ early systolic wall thinning $\left.+0.20, r=0.69, p<0.05\right)$ or the left circumflex coronary artery (LCX stunning, $n=7$, Postsystolic wall thickening $=0.87 *$ early systolic wall thinning $+0.45, \mathrm{r}=0.99, p<0.05)$. 
B. Correlation between postsystolic wall thickening and early systolic wall thinning in the non ischemic remote zones measured either in the left anterior descending coronary artery (LAD stunning, $n=7$ ) or the left circumflex coronary artery (LCX stunning, $n=7$, Postsystolic wall thickening $=1.40 *$ early systolic wall thinning $+0.31, \mathrm{r}=0.93, p<0.05)$.

C. Correlation between the duration of postsystolic wall thickening and the delay in wall thickening (Duration in postsystolic wall thickening $=0.14 *$ delay in wall thickening $+61, \mathrm{r}=$ $0.97, p<0.05)$.

Figure 7

Flow-chart of postsystolic wall thickening interpretation according to its location (anterior or posterior walls) and its amplitude in the normal, the ischemic and the stunned myocardium according to ROC analysis (Sens : sensitivity; Spec : specificity).

\section{Figure 8}

Representative tracings computed from Tissue Doppler Imaging recordings in basal, mid and apical segments of the anterior and posterior walls. Measurements were performed at baseline, in the stunned anterior wall (LAD stunning) and in the stunned posterior wall (LCX stunning). For each beat, the first and the second shaded lines represent aortic valve opening and closure, respectively. 


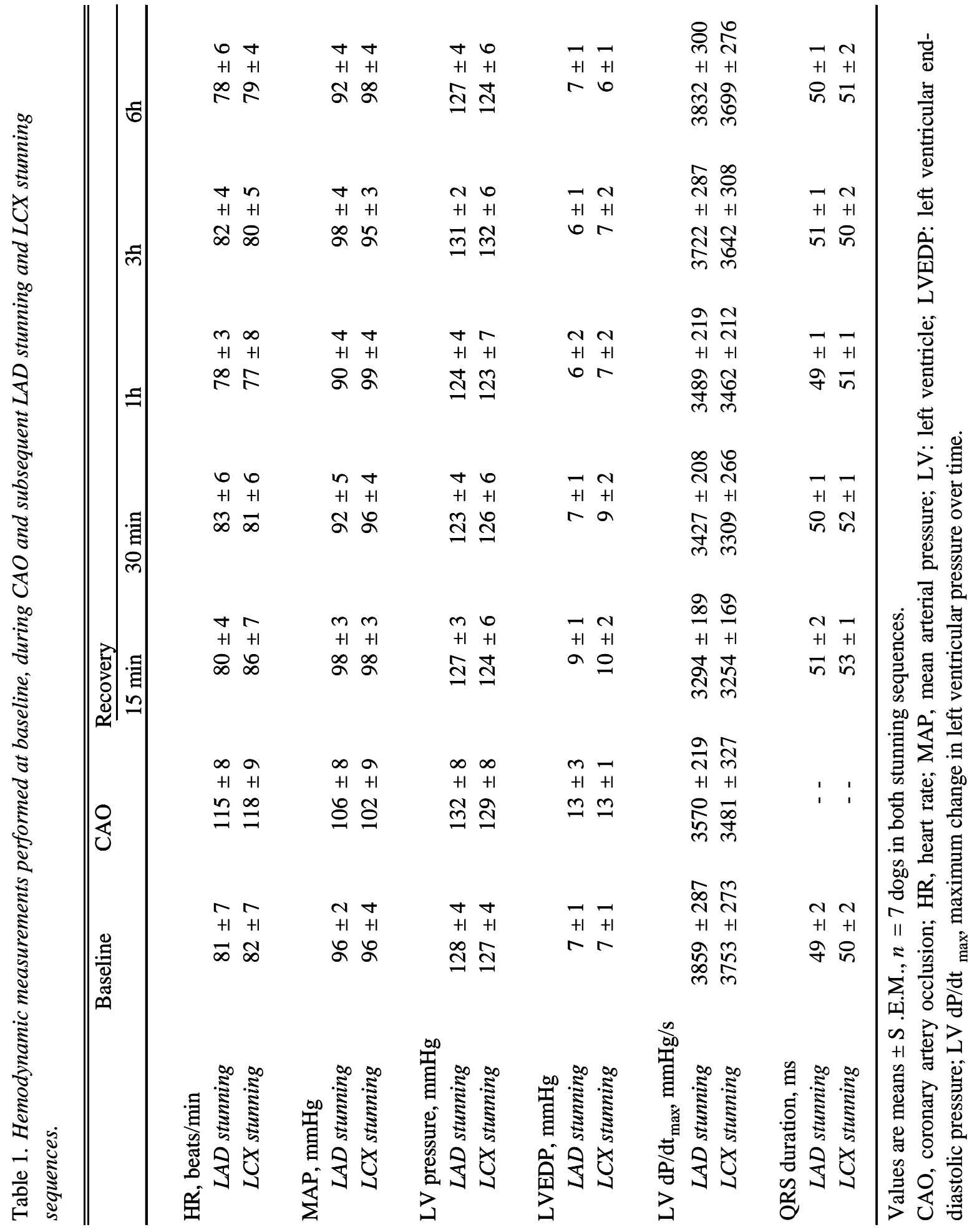



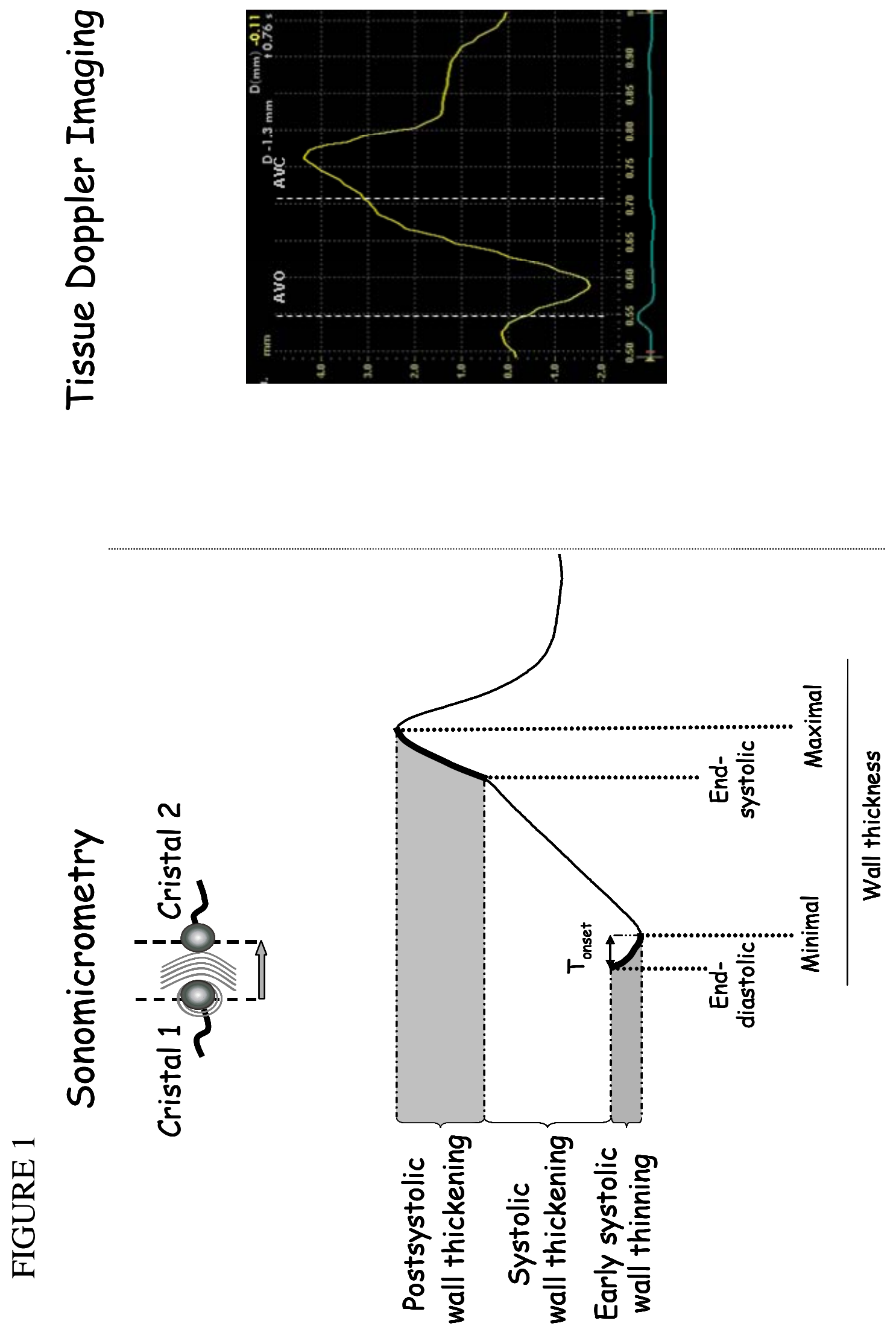

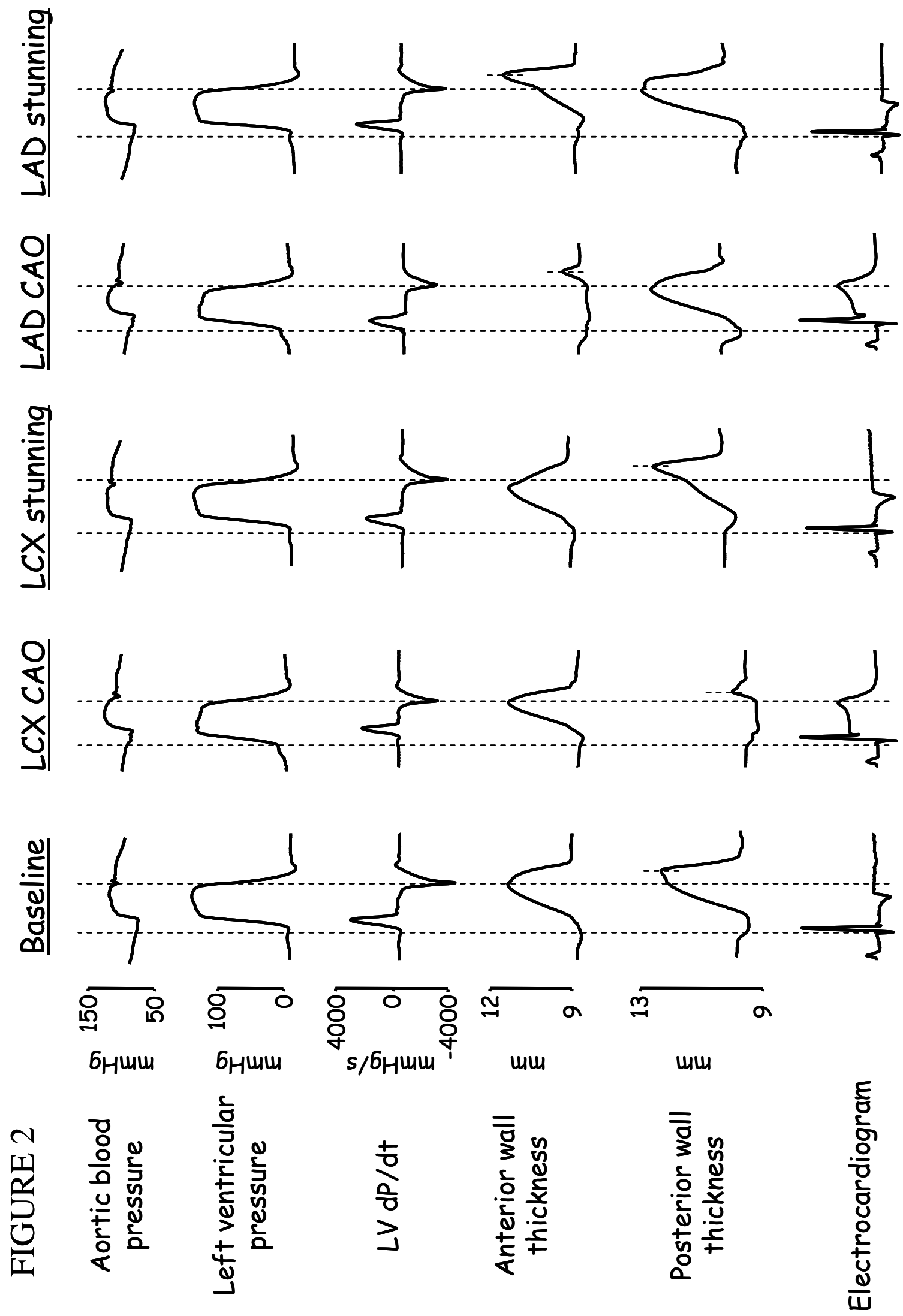


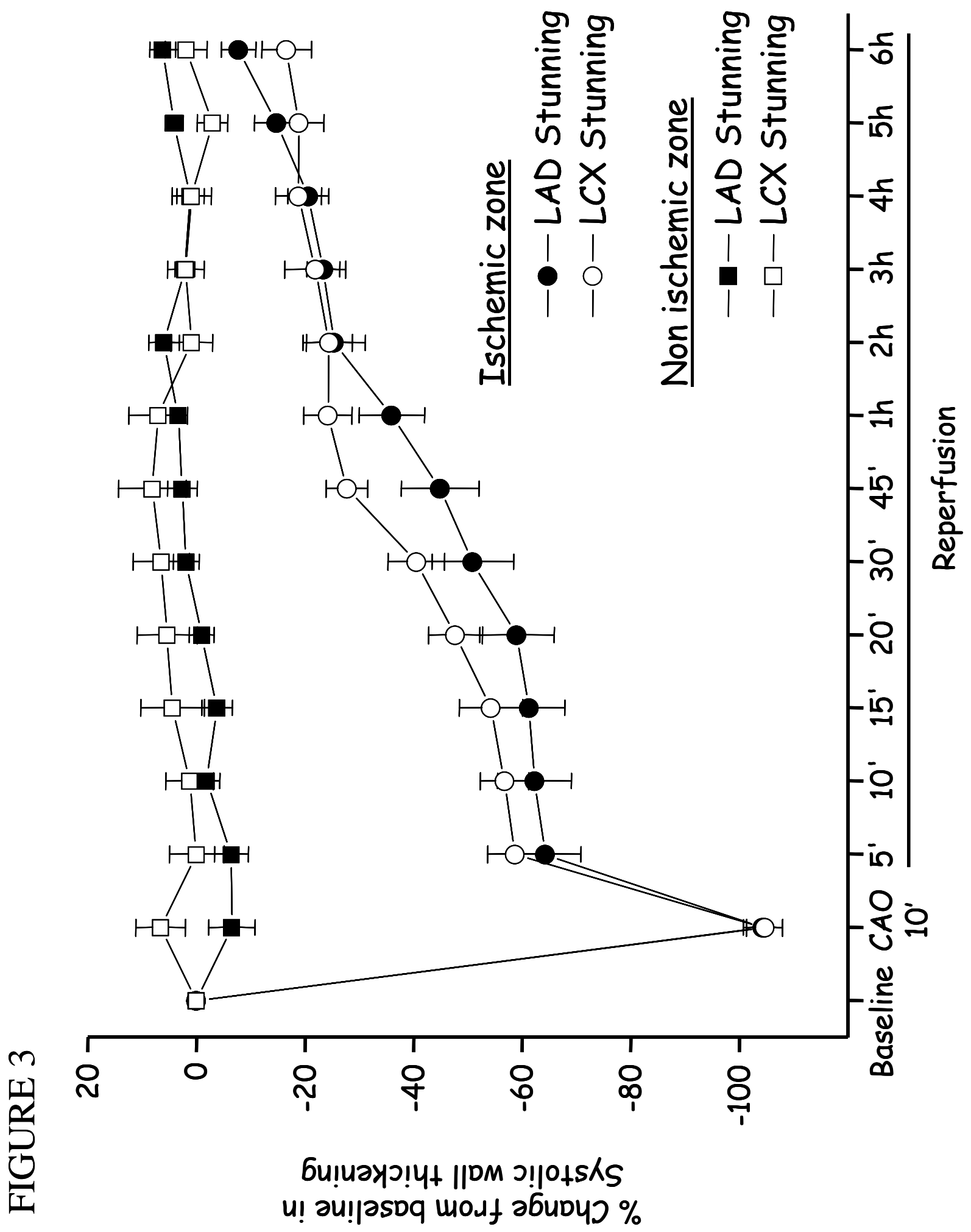


Ischemic zone

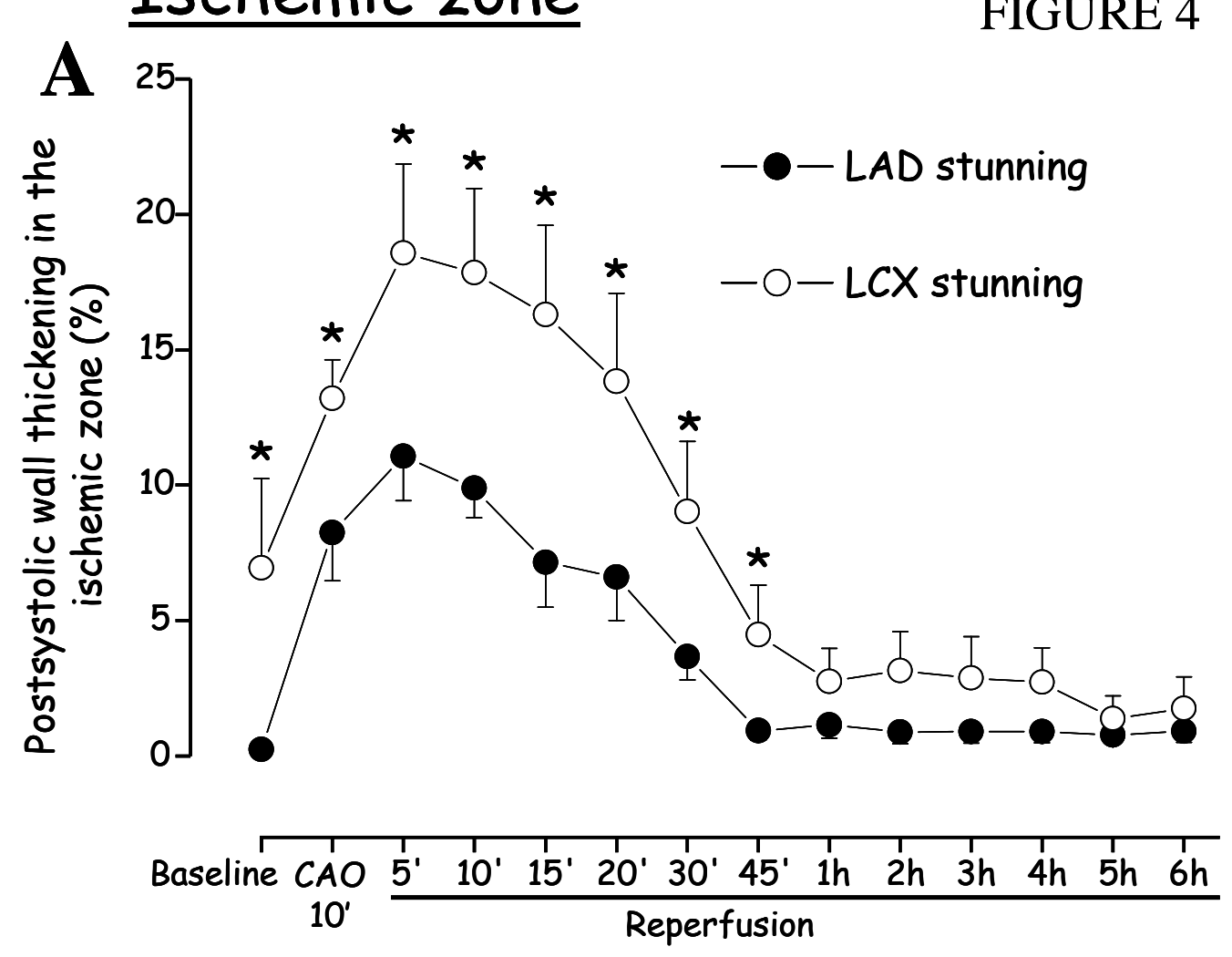

FIGURE 4

Remote non ischemic zone

B

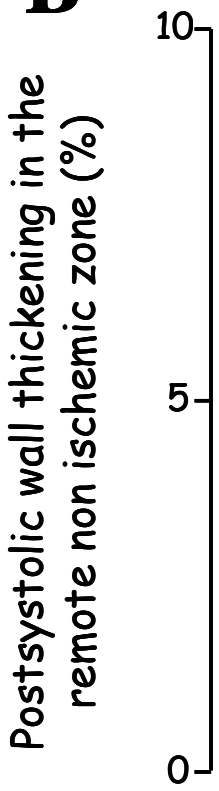

- - LAD stunning

$-\square-$ LCX stunning

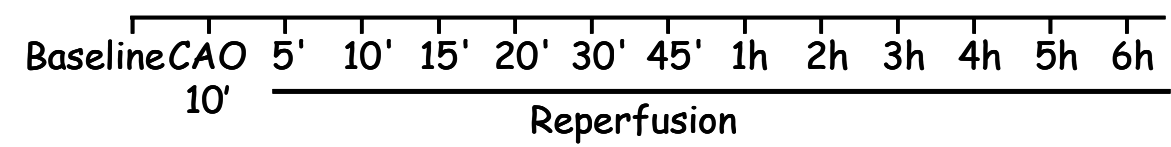



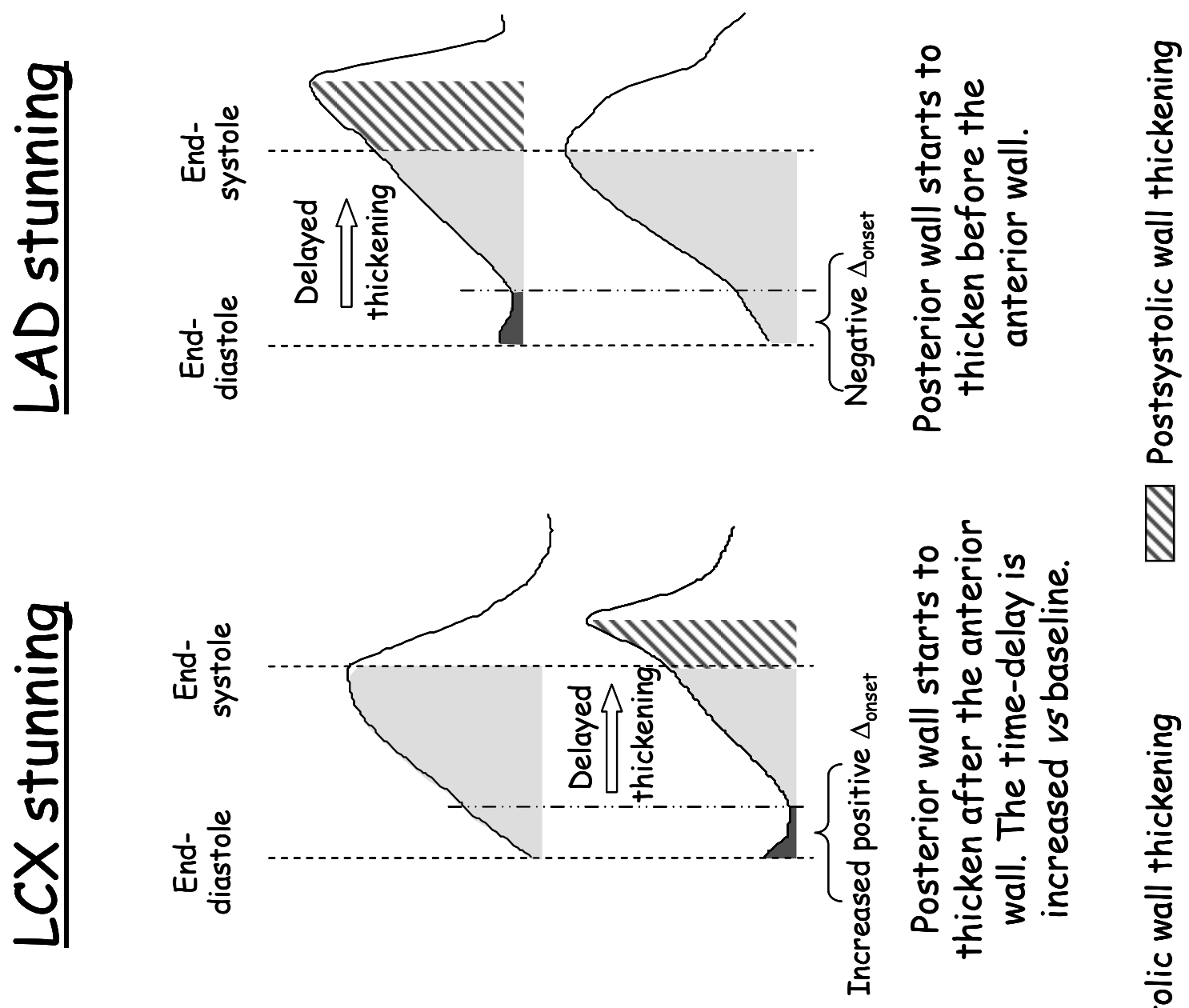

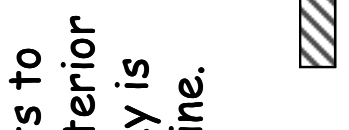
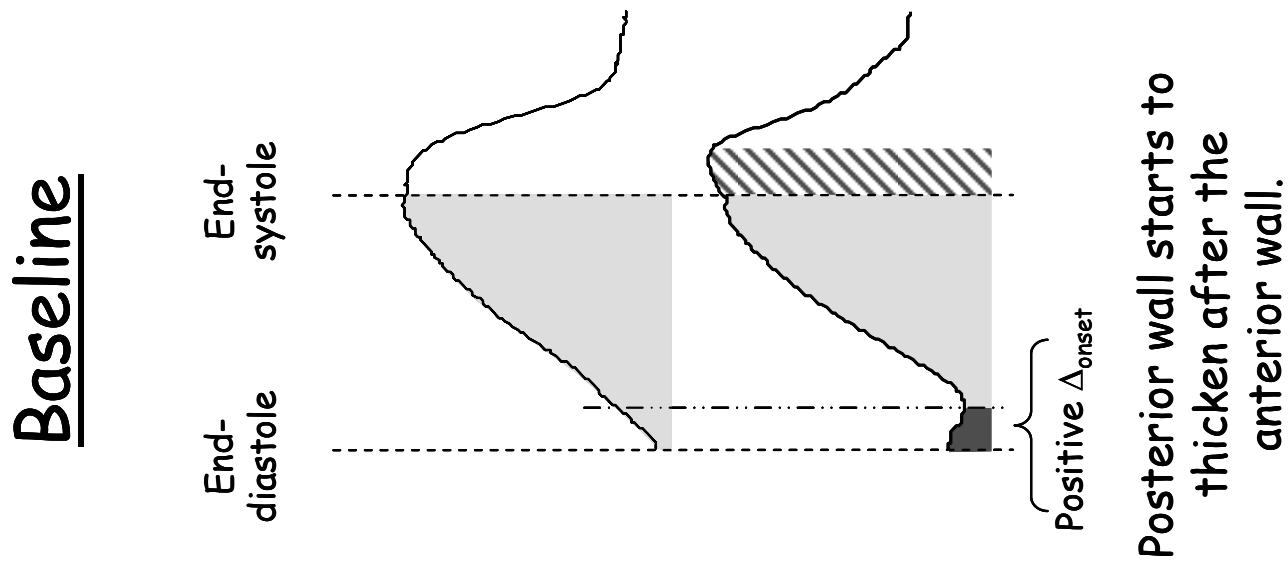

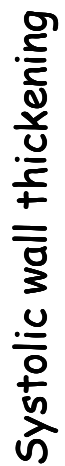

م
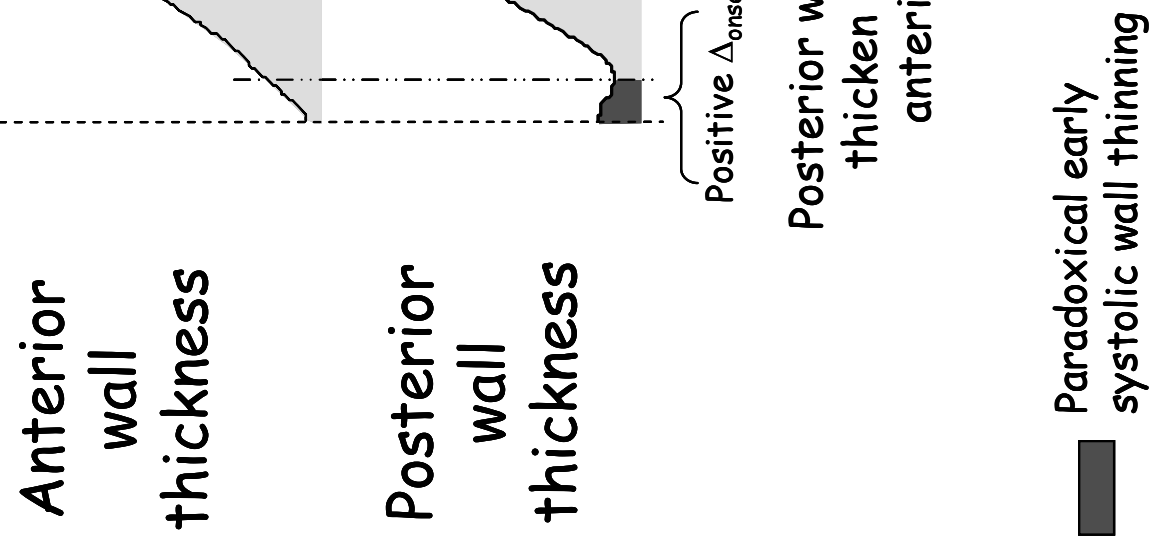


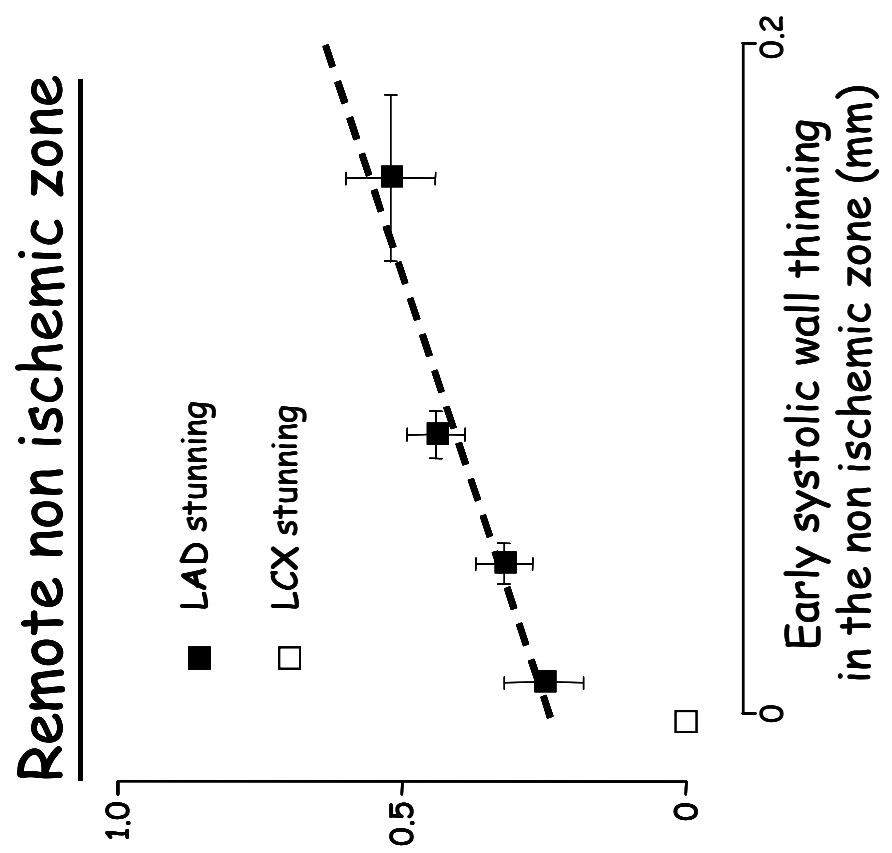

(m) anoz ग!mayวs! uou atomay

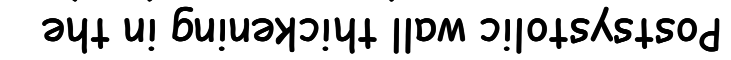
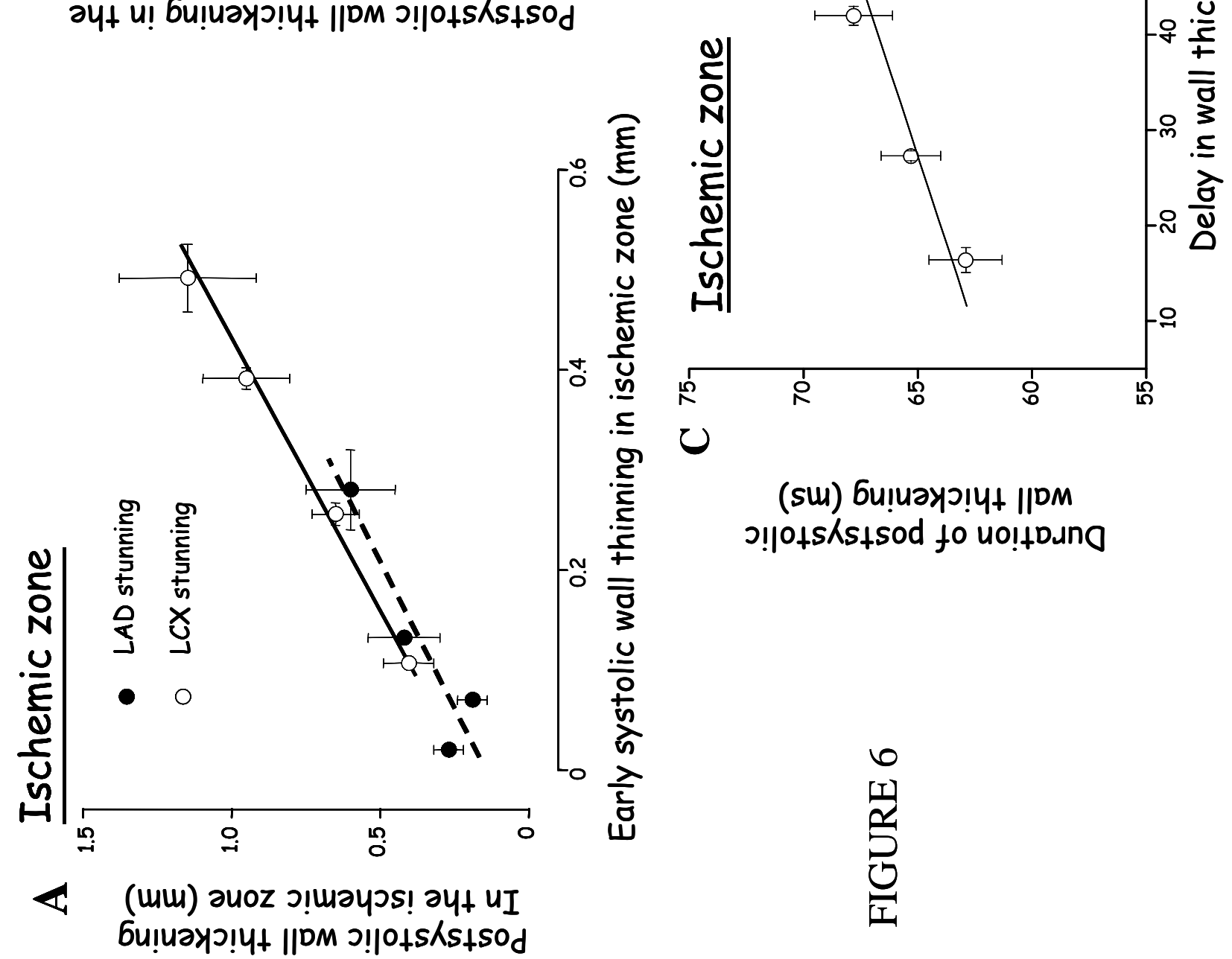


\section{FIGURE 7}

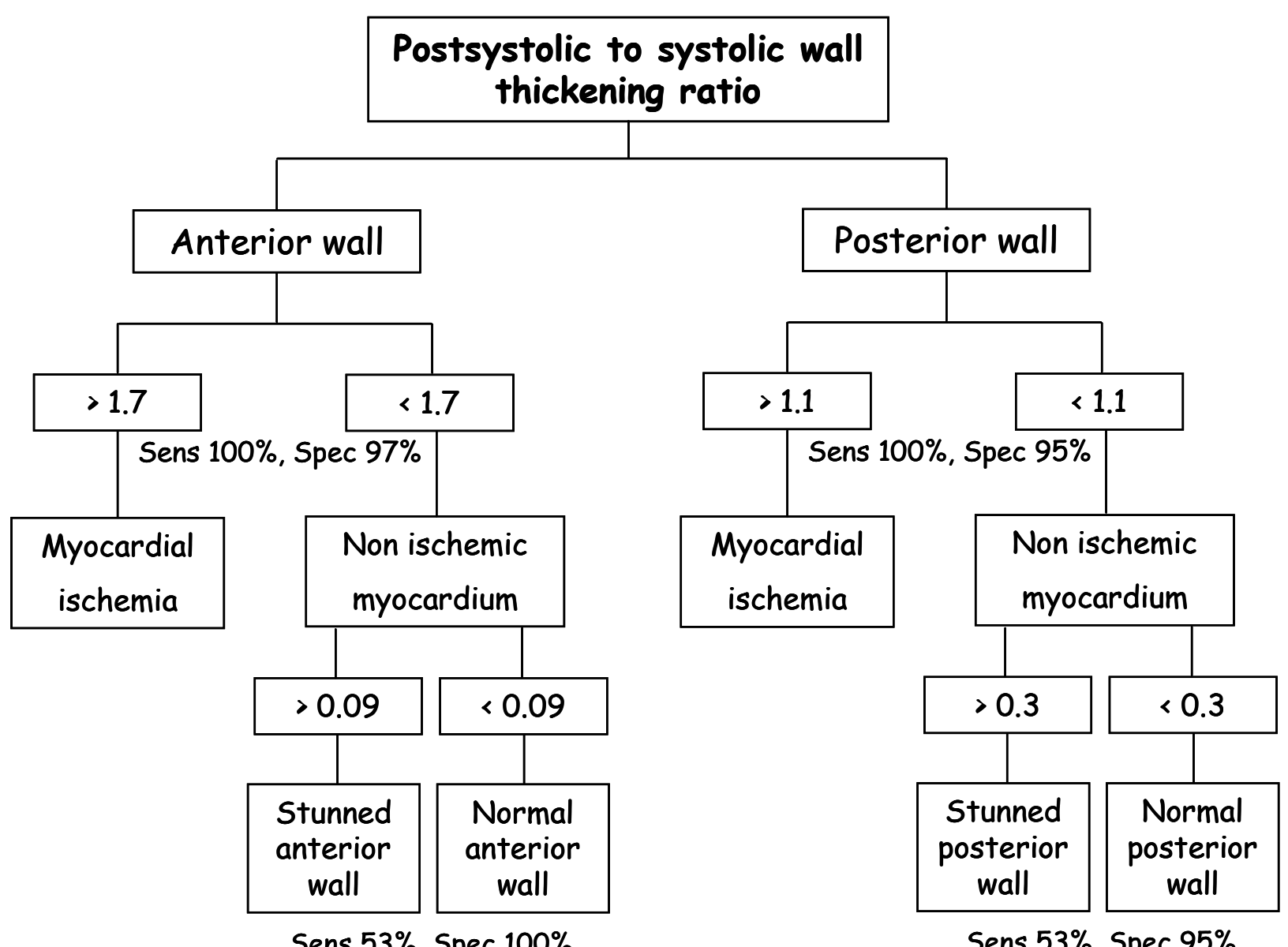



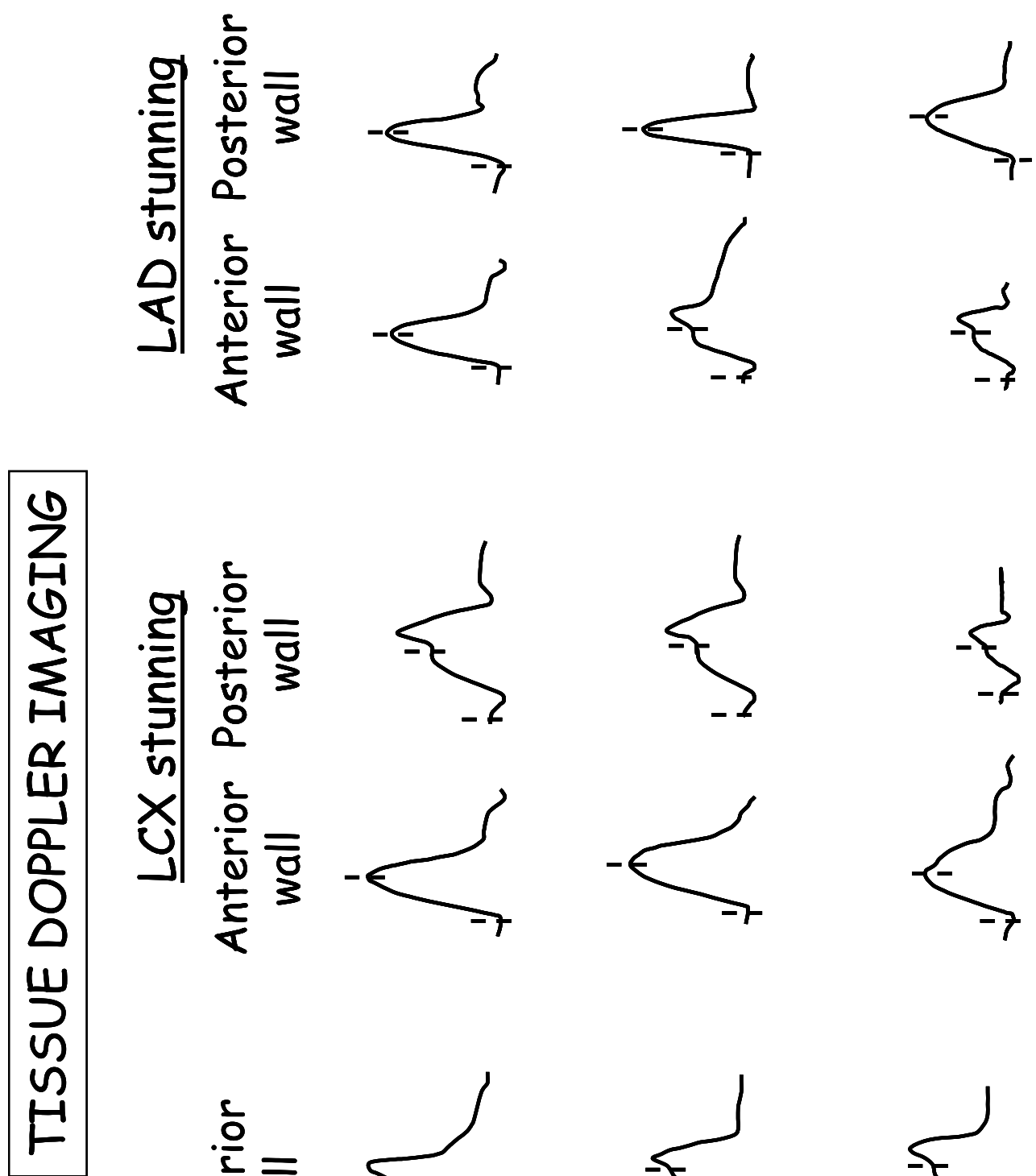

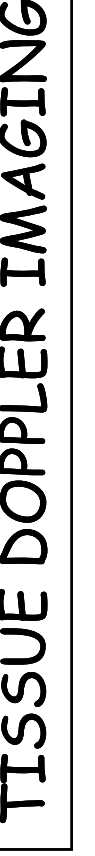

$\frac{1}{2}$
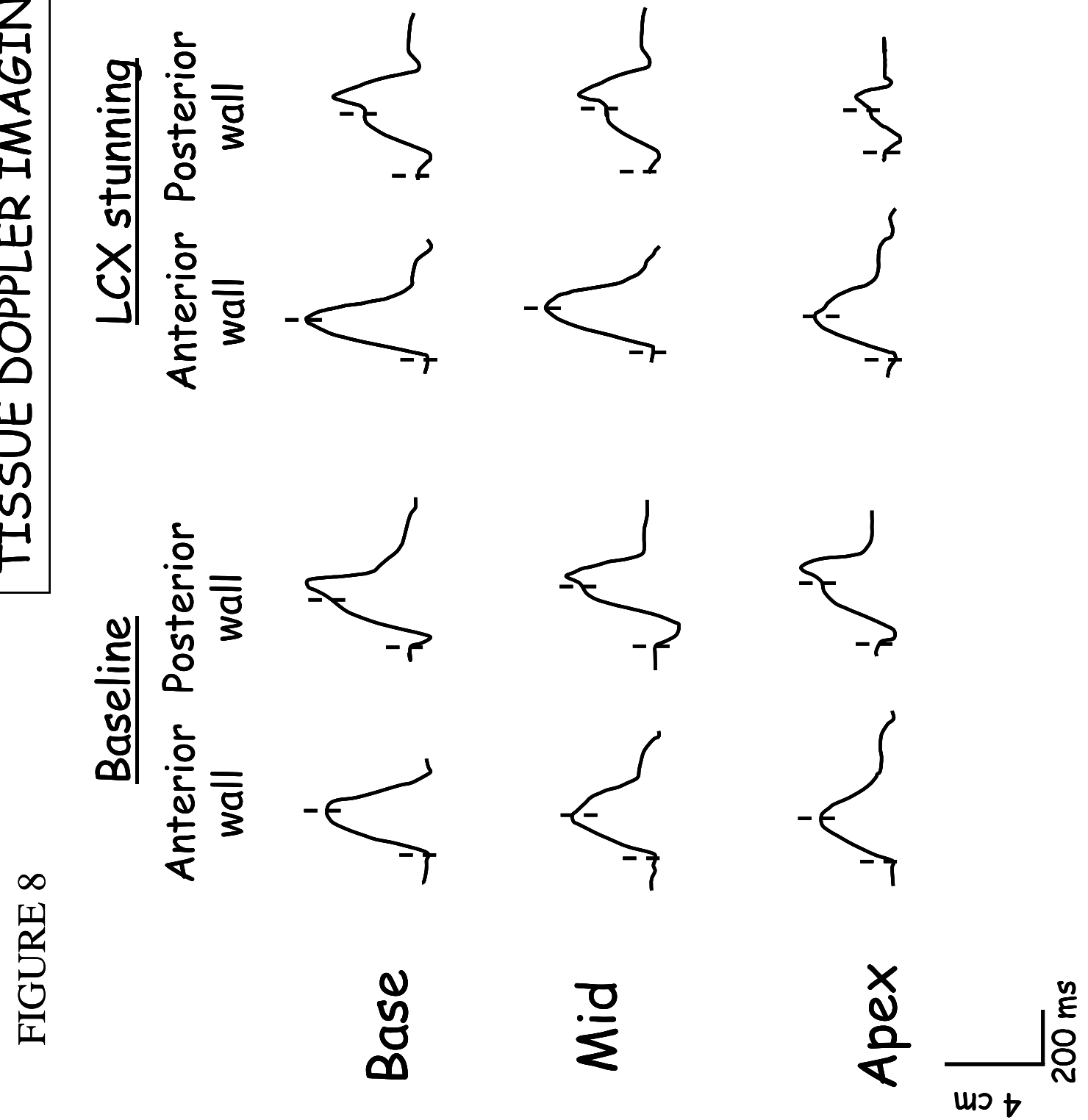